\title{
The Role of Individual Differences in Learning
}

\author{
Péter Tóth
}

Trefort Ágoston Centre for Endineering Education, Óbuda University

Népszínház u. 8, H-1081 Budapest, Hungary

toth.peter@tmpk.uni-obuda.hu

\begin{abstract}
A precondition for the realization of the adaptive teaching process is a knowledge of the individual characteristics of learning, an understanding of the individual methods of learning and, through these, the selection and formation of a suitable teaching environment. Therefore the differences between students must be taken into consideration by the teacher. They are to be interpreted not only at the level of intellectual capacities but also with respect to the most different individual characteristics of sensation, perception, thought and learning. In the present empirical research the 12-item variant of Kolb's LSI questionnaire is applied for this purpose. First Kolb's learning model is briefly surveyed, then the objective of the research is stated, the results of the empirical research are shown and, finally, the most important statements of the research are presented.
\end{abstract}

Keywords: adaptive teching process; learning strategies; Kolb's learning styles

\section{Preliminaries and Theoretical Background}

In a former paper [1] the adaptive teaching process as well as the teaching strategies in this process were explained. Strategy was interpreted as such a complex system of procedures as organically combines method, work form and teaching aids. The preferred individual patterns of strategies characteristic of the individual were explained as style (of teaching and learning). Our former results [1] showed that certain learning strategies (e.g. the preferred way of information acquisition, perception modality [10]) reflect some kind of stability, whereas others (e.g. the preferred way of information processing and its application) show continuous variation.

A common feature of the many learning style theories is that students are classified according to their cognitive characteristics, based on single- or multidimensional bipolar (usually cognitive) scales. [2] Students' effective learning methods, forms and teaching aids are to be concluded from the preferred strategies that belong to learning style. The teaching strategies which elicit the most preferred learning strategies are also to be defined, based on which the learning environment or the learning process are to be designed. 
Coffield formed five groups of the existing sixty to seventy theories. [2] Of these now the category is highlighted for the present research which interprets learning style as a flexibly stable learning preference. [3] [4] [5]

From the point of view of our research, the theory examining the learning preferences of the individual is to be highlighted. The most significant theory in this group is associated with the name of David Kolb, who has been studying learning style for more than 40 years. His Learning Style Inventory (LSI) is one of the most widespread measuring instruments in the examination of learning styles. His experimental theory of learning amalgamated the relevant and decisive movements of the 20th Century (John Dewey, Kurt Lewin, Jean Piaget, William James, Carl Jung, Paulo Freire, Carl Rogers, etc.) [6] [7]

His theory rests on six principles:

- Learning is interpreted as a relationship between the individual and the environment.

- Learning is interpreted as the holistic process of adaptation to the environment.

- Learning is to be regarded rather as a regulated process than an outcome condition.

- The student's existing knowledge and experience play a decisive role in processing new information.

- Piaget's adaptive theory is regarded as the basis of learning. Adaptation has two forms, namely assimilation and accommodation.

- Learning is a process of constructing knowledge, the result of which presents itself as a relationship between community knowledge and individual knowledge.

Kolb gives two important dimensions of learning: perception and processing. These dimensions are visualized as two intersecting axes, where each axis has two poles: perception (information acquisition) ranges from concrete experience (CE) to abstract conceptualization (AC), and information processing ranges from active experimentation (AE) to reflective observation (RO). The two axes form a fourquadrant field for mapping individual learning styles. On the basis of preferences along axes four kinds of learning style were differentiated: Converger, Diverger, Assimilator and Accommodator. [8] [9] 


\section{Aims and Means of Examination}

David Kolb's LSI (Learning Style Inventory) underwent a lot of change and development during the years. [7] In our former examination [1] the 9-item questionnaire, whereas in the present research the 12-item one was used to decide the learning style of the age group 14 to 18 in basic professional education. The results were compared with those of the former longitudinal research.[1] However, it was not possible to draw real conclusions, because this survey contrary to the previous one - was not representative (pilot test).

In adapting the questionnaire it was kept in mind that the participants were not students at higher or adult education (as most of them are in Kolb's tests), but at vocational secondary schools.

The questionnaire comprises 12 statements with 4 possible endings each. The student has to rank the following possibilities: $4=$ most like you, $3=$ second most like you, $2=$ third most like you, $1=$ least like you. They are worth 4, 3, 2 points or 1 point in that order. These points are added up as columns at the bottom of the table. The four columns show the above mentioned four kinds of learning variables and methods. [9]

The participants at the present pilot examination were grade 9, 10 and 11 classes of 29,25 and 25 persons respectively at a vocational secondary school of informatics.

The basic purpose of the examination was, making use of the experience and results of the former research, to test in basic professional education the 12-item version of Kolb's questionnaire and thereby prepare a representative longitudinal examination.

Based on all these the hypotheses and a question of the empirical research focussing on vocational secondary school students who specialize in informatics are created according to the following.

H1. Learning variables in both dimensions are not normally distributed (students specializing in informatics have general preferences) and form a bipolar system.

H2. In the dimension of preferred information type and information acquisition, perception the learning variables act similarly to attitudes. In this dimension the preferred learning variable is experience acquisition based on concrete experiences.

H3. In the dimension of preferred information processing learning variables vary in a different way with a progress in studies. Productive application and experimentation is a preferred learning variable.

Q1. How does the ranking of learning style change with the progress in studies? Can any characteristic realignment or move be observed? 


\section{Results of Empirical Examination}

\subsection{Description of Learning Variables}

First the descriptive statistical and normality examination of Kolb's learning variables (AC, RO, AC, $\mathrm{CE}$ ) and difference variables (AE-RO, AC-CE) were performed. Both the analysis of descriptive statistical data (Skewness / Std. Error of Skewness, Kurtosis / Std. Error of Kurtosis; Table 1) and the Kolmogorov Szmirnov as well as the Shapiro - Wilk tests (Table 2) unanimously justify that the less strict conditions of normality are fulfilled for all the variables while the stricter ones are fulfilled for the majority of them (CE, AC, AC-CE; AE-RO). The null hypothesis of the Kolmogorov - Szmirnov test is that the variable is not of normal distribution and the distribution of data based on significance level and marked by $*$ does not differ from normal distribution.

Table 1

Descriptive statistical data of learning variables and difference variables

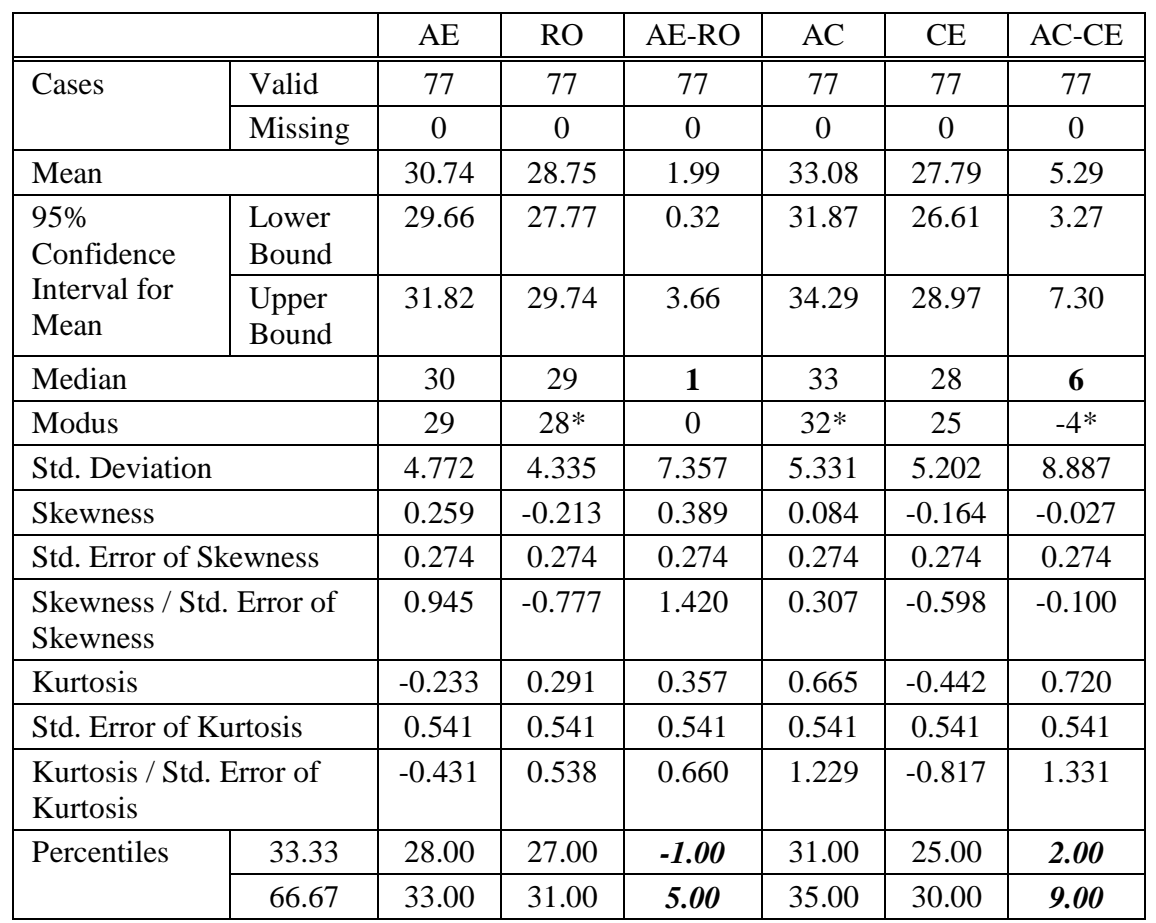

Note: Quotients of Skewness and Std. Error of Skewness as well as of Kurtosis and Std. Error of Kurtosis also fall within the strict limit value of $\pm 1,96$, therefore the more permissive conditions of normality are fulfilled.

* The smallest is given of the several modes. 
As seen from the positive values of difference variables, students specialized in informatics have a stronger preference for the productive application of what they have acquired (AE), and even more so with respect to thought and concept formation (AC), which may also harmonize with the character of the profession. If these value pairs are compared with those gained at a former test [1], a more significant difference will appear with respect to AC-CE mostly. To value pairs (AE-RO;AC-CE) $(+1 ;-2)$ were added at a former test, whereas $(+1 ;+6)$ at the present one. (See Table 1 for median value.) In Kolb's 2005 examination the cutpoints for learning style types were $(+6 ;+7)$. [7]

Table 2

Test of Normality

\begin{tabular}{|l|c|c|c|c|c|c|}
\hline \multirow{2}{*}{} & \multicolumn{3}{|c|}{ Kolmogorov - Smirnov $^{\mathrm{a}}$} & \multicolumn{3}{c|}{ Shapiro - Wilk } \\
\cline { 2 - 7 } & Statistic & $\mathrm{df}$ & Sig. & Statistic & df & Sig. \\
\hline \hline CE & 0.081 & 77 & $0.200^{*}$ & 0.984 & 77 & 0.431 \\
\hline RO & 0.093 & 77 & 0.094 & 0.982 & 77 & 0.364 \\
\hline AC & 0.084 & 77 & $0.200 *$ & 0.982 & 77 & 0.342 \\
\hline AE & 0.110 & 77 & 0.022 & 0.978 & 77 & 0.217 \\
\hline AE-RO & 0.087 & 77 & $0.200 *$ & 0.979 & 77 & 0.220 \\
\hline AC-CE & 0.059 & 77 & $0.200 *$ & 0.987 & 77 & 0.638 \\
\hline
\end{tabular}

a. Lilliefors Significance Correction

* This is a lower bound of the true significance.

\subsection{Learning Variables Through Time}

The comparison of the statistical data of Kolb's learning variables was carried out according to the cross sectional model for each grade, too. The results partly coincide with and partly differ from the former ones. [1]

There is no difference from the former test results in the preferred mode of information processing. The mean values and standard deviation values of $\mathrm{AE}$ és RO variables are similar to the former ones. With the progress of studies a gap opens, that is the preference difference between the two variables increases. Standard deviation values are balanced with time (Fig. 1).

In the dimension of the preferred type of information acquisition, perception the change in the mean as well as the standard deviation values of the variables through time is also similar to the former change. However, the fact is not negligible that formerly it was the preference for syllabus acquisition based on concrete experience (CE) which was stronger than that for abstract conceptualization, but now the situation is quite the contrary (Fig. 2). This may be related to the syllabus specialities of the subject of informatics, which reinforces learning preferences of this type. 


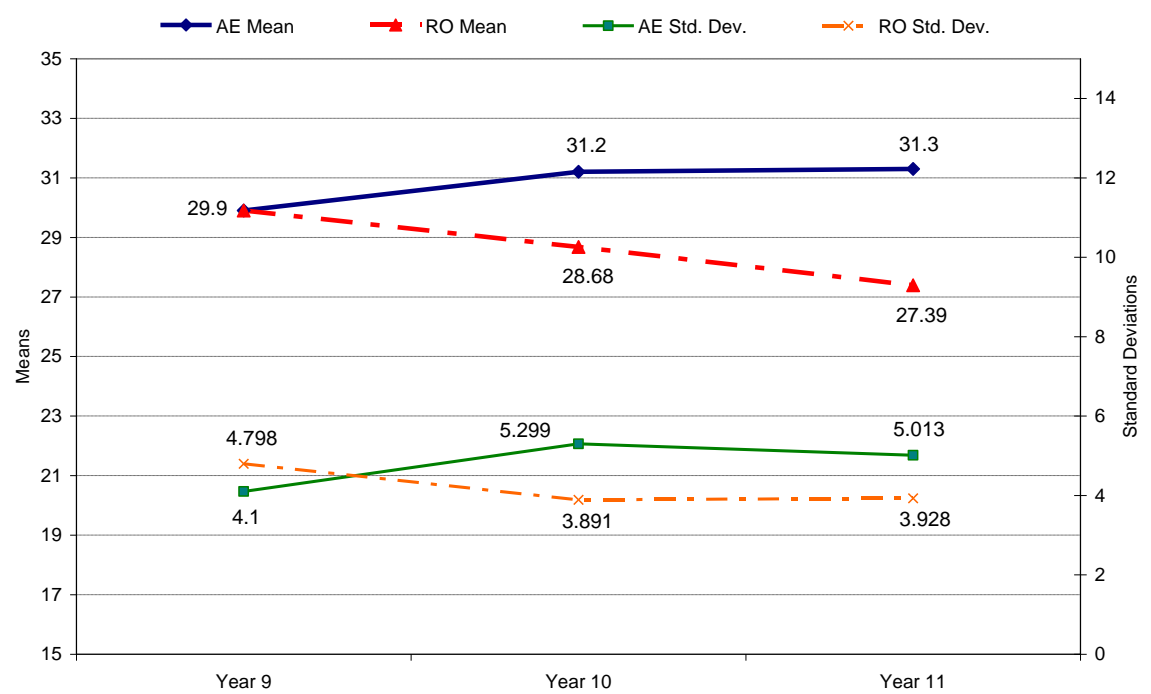

Figure 1

Means and standard deviations of learning variables I

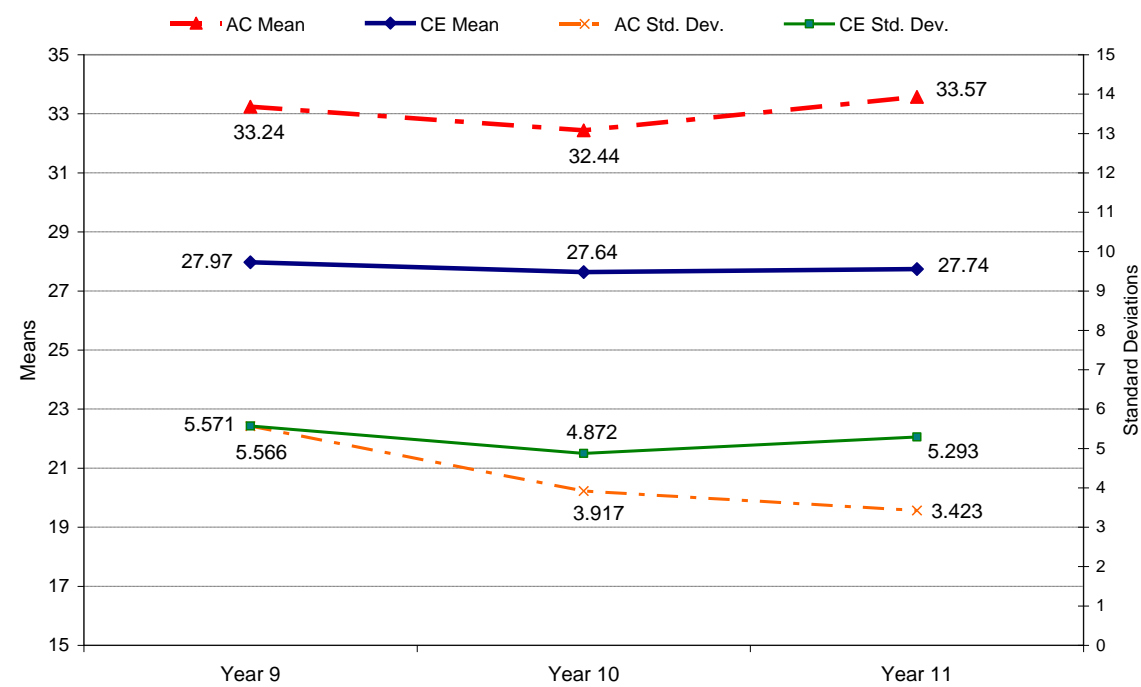

Figure 2

Means and standard deviations of learning variables II

$\mathrm{AC}$ and $\mathrm{CE}$ variables hardly change through time and may be considered attitudinal, whereas the same cannot be stated of $\mathrm{AE}$ and $\mathrm{RO}$ variables.

Tests of normality were performed for learning variables as well as difference variables in each grade, too. 
The results show that in grade 9 conditions of normality are fulfilled for all variables while in grade 11 for almost none. From this the conclusion is to be drawn that balanced distributions still present in grade 9 tend to polarize in higher grades.

An analysis of variance was also carried out with the purpose of examining how learning preferences change with the progress of studies. As seen earlier, a precondition for variance analysis, the normal distribution of the learning variables, is fulfilled whereas the second condition, that is the homogeneity of variance, is justified by Levene-test, therefore there is no objection to performing an analysis of variance.

The results justify the former statements according to which the averages of variables $\mathrm{AC}$ and $\mathrm{CE}$ do not show a significant difference, while those of $\mathrm{RO}$ do, that is the role in the learning process of reflective observation and understanding (RO) changes (decreases) with the progress of studies, while that of active experimentation or productive application (AE) slightly increases.

Scheffe's a priori contrast test also throws some light on which grades' averages within a category have a significant or no deviation $(\mathrm{p}<0.05)$. The results prove that with respect to variable RO grades 9 and 11 show most deviations.

Finally the change through time of difference variables was examined with the progress of studies. Difference between these variables is seen to decrease significantly with students specializing in informatics in higher grades. It is all attributable to the increase in $\mathrm{AE}$ preference at the cost of $\mathrm{RO}$, which means that practical application continuously gains dominance over reflective observation, the multi-aspectual examination of things and the search for their meaning. In its background it may be found that there is an increased number of practical courses such as for example computer programming or data base management in higher grades. Among the requirements for the development of the general education plan of the training is the improvement of students' skills at and familiarity with

- writing, running and testing the source code aiming at the solution of the algorithm designed by them,

- the conscious application of programming items,

- problem solving in the various programming environments,

- the creation of data tables, relation formation and normalization,

- the application of the basic elements of data base management systems,

- generating queries.

These syllabuses certainly offer a favourable opportunity for active experimentation, the application of skills in new situations which require different learning methods of students, in other words the preferred information processing methods alters. 


\subsection{The Problem of Defining Learning Style}

The definition of learning styles was done on the basis of both Kolb's original values [8] and those of our own cut-points for learning style types. $72.73 \%$ of students (56 persons) did not change their learning style type. Of the remaining 21 students 12 shifted from the accommodator learning style to the diverger one, 4 from converger to assimilator, 3 from converger to accommodator and 2 from assimilator to diverger. In these cases the (AE-RO;AC-CE) value pairs apparently approximated an axis. Table 3 suggests that the converger style seems to be the most insensitive and the diverger style the most sensitive one to define the cutpoints for learning style types. All the students classified as converger on the basis of our own results was ranked the same style according to Kolb's cut-points, too. The ranking of $41.18 \%$ of diverger students would change on the basis of the original Kolb's cut-points.

Table 3

Change in learning style classification

\begin{tabular}{|c|c|c|c|c|c|}
\hline & \multicolumn{4}{|c|}{ Classification of learning styles (own, 2013) } \\
\hline & & Converger & Accommodator & Assimilator & Diverger \\
\hline \multirow{4}{*}{ 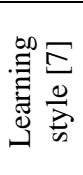 } & Converger & 10 & 0 & 0 & 0 \\
\hline & Accommodator & 3 & 8 & 0 & 0 \\
\hline & Assimilator & 4 & 0 & 18 & 0 \\
\hline & Diverger & 0 & 12 & 2 & 20 \\
\hline
\end{tabular}

It was showed by Pearson Chi-square test $(\mathrm{p}<0.05)$ that the two types of learning styles classification significantly correlated with each other $\left(\chi^{2}=116.447 ; \mathrm{df}=9\right)$ and the Kolb's and my own classification coincide by the $63.2 \%$ of certainty $(\lambda=0.632, \mathrm{p}<0.01)$.

The classification of learning styles - based on our own value pair $(+1 ;+6)$ - was compared according to grades as well (Figures 3-4). It is to be said that with the progress of studies the proportion of converger students significantly increases while that of assimilators, and even more of divergers, decreases.

The converger student is a real technical professional, who prefers logical thought of which he makes most in performing activities of a practical sort. He uses data founded on practical and tangible experience in order to construct his own system of skills and information. In his judgements he relies only on concrete facts and is not too keen on uncertain and inaccurate information. Being a „decision-maker”, he enjoys problem situations. He is able to focus on the solution of problems by first thinking them over and then solving them. He is characterized by deductive thought, that is he readily applies the general skills, laws and rules to particular situations during problem solving. He is a pragmatist, with a narrow scope of interests and less flexible thought than that of his diverger companion. In case of the overwhelming dominance of this learning style (there were altogether 3 
students of this kind) he often makes unfounded and hasty decisions and makes a mistake in the interpretation of the problem situation at hand. However, in a contrary situation, he is unable to concentrate on and solve a problem or adequately check his own ideas.

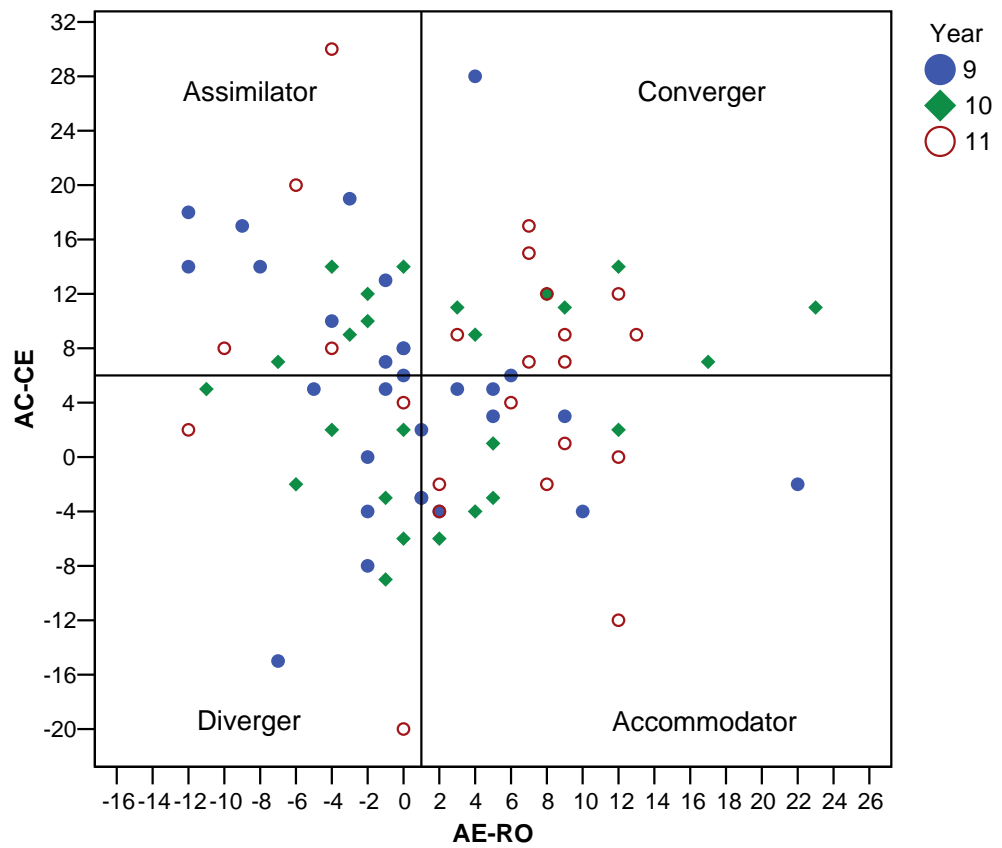

Figure 3

The classification of learning styles according to grades I

As seen from the above, students' learning style shifted in the direction mostly according to the specialities and requirements of subjects. Since learning style is an individual characteristic, a longitudinal examination would be even more precise in showing how this change took place from student to student. If this was reinforced, the stable and attitudinal personality indicator property of learning style could by all means be declared false. 


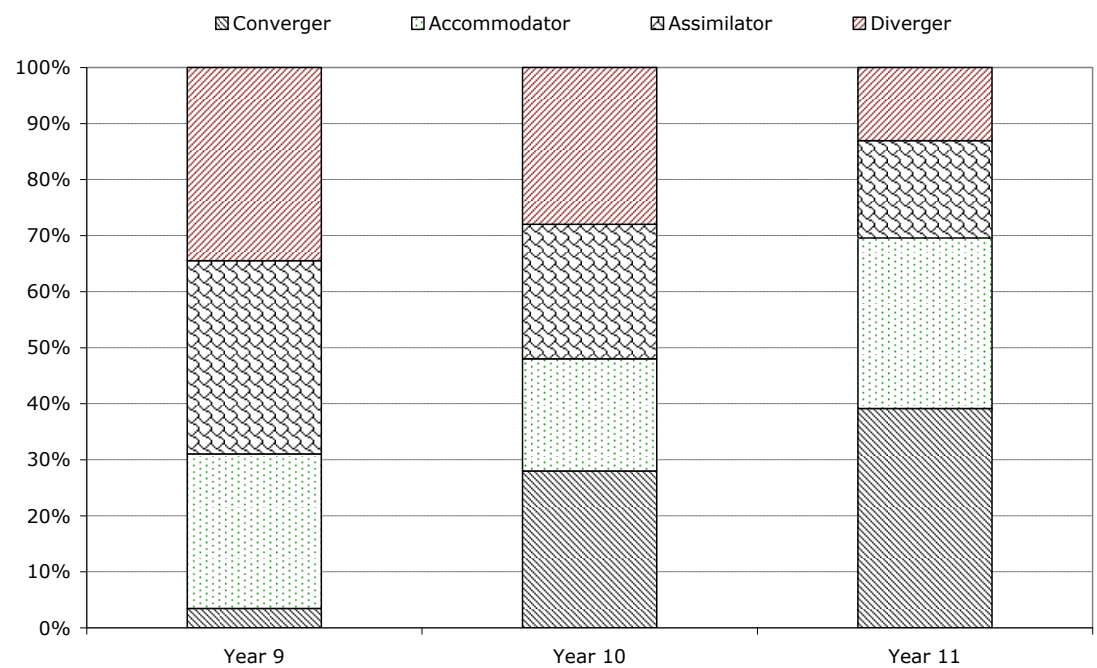

Figure 4

The classification of learning styles according to grades II

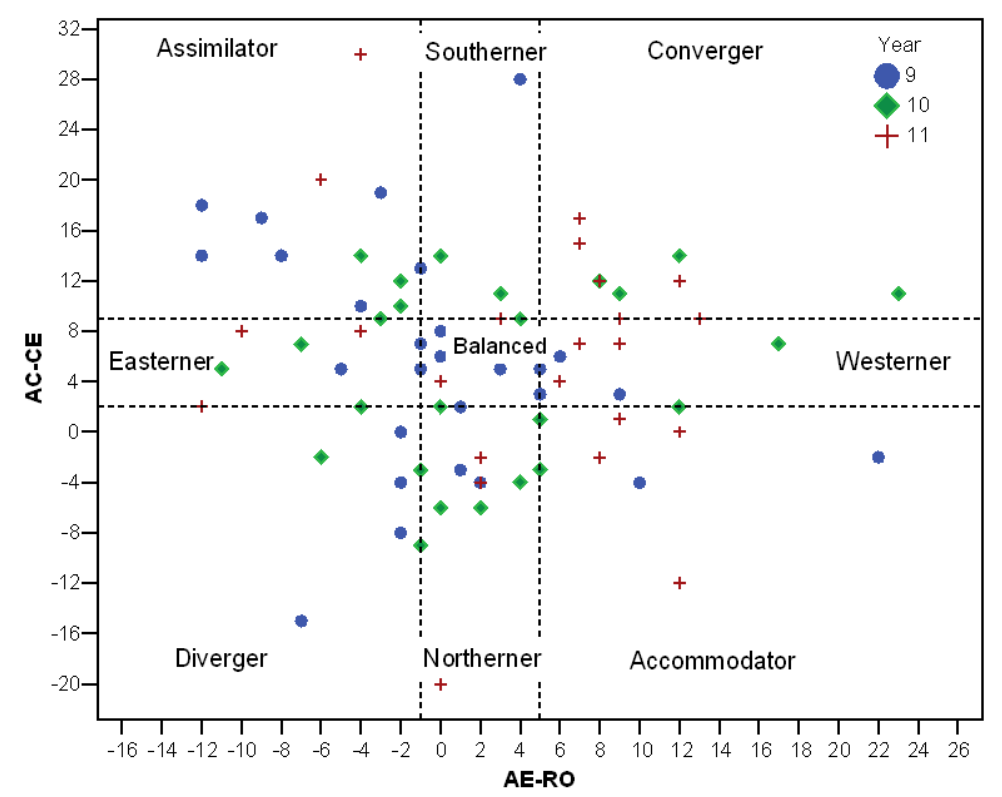

Figure 5

Learning styles in the nine-region model 
Learning style classifications were analyzed by the nine-region Kolb model, too. As seen in the case of the four-region model and in our previous examination [1], many (AE-RO;AC-CE) value pairs fall in the proximity of one axis or both axes. In the nine-region model these were classified as Northerner, Southerner, Easterner, Westerner, or Balanced learning style. In this model the groups of those who have a definite or partly definite learning preference or who do not have one at all can be sharply distinguished (Fig. 5).

Following the statistical analysis of classifications it is to be observed that $53.25 \%$ of students have a strong preference in two directions, in other words they preserved their four-region preference, $40.26 \%$ have a one-direction strong preference, while $6.49 \%$ have no preference at all. The majority of students belong to Assimilator, Converger and Northerner (strong CE preference) learning style.

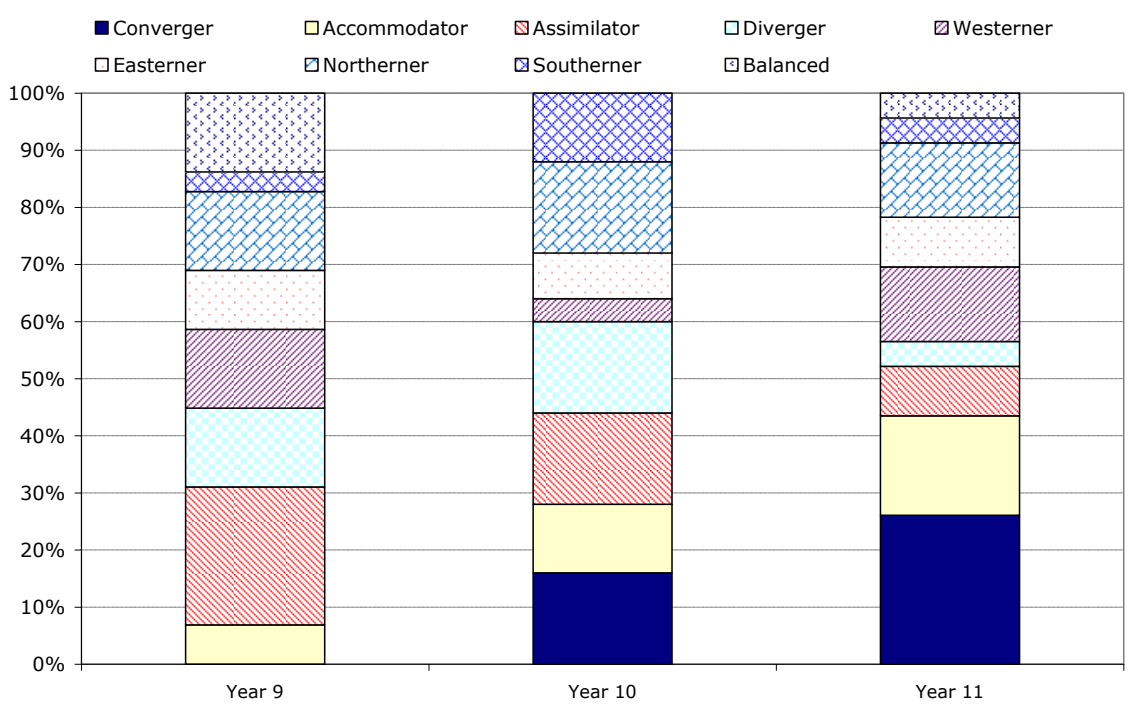

Figure 6

The distribution of learning styles according to classes in the nine-region model

The change of learning styles within the nine-region model through time was also tested (Fig. 6). The ratio of students with a two-direction strong preference rose from $44.83 \%$ measured in grade 9 to $56.53 \%$ by grade 11 . It hardly altered in the case of those with a one-direction preference (from $41.38 \%$ to $39.13 \%$ ), whereas the ratio of those of the balanced style without a preference significantly decreased (from $13.79 \%$ to $4.35 \%$ ). Based on all that it is to be stated that the learning variables of students specializing in informatics polarize with the progress in studies by shifting from the balanced region first to the Northerner, Southerner, Easterner, Westerner and then to regions of a strong two-direction preference $\left(\chi^{2}=14.579 ; \mathrm{df}=6 ; \mathrm{p}<0.05\right)$. Again, only a longitudinal examination may provide absolute certainty. 
In Fig. 7 the percentage distribution of our results in the nine-region model were compared with the results of the research Kolb did among 288 first-grade university students. [8] As can clearly be seen from the figure, with the exception of students of the Assimilator and Converger style, there are significant differences to be depicted. The results of $1286 \mathrm{MBA}$ and 216 arts students in higher education were also published. [8] Our results tend to approximate those in the further regions.

\section{Conclusions}

In the course of our research among students specializing in informatics a latest version of Kolb's questionnaire for the empirical learning-model was tested (LSI 3.1). Making use of the results of our former longitudinal examination three hypotheses and one question were formed at the beginning of the research, the answers to which are given below.

H1. Learning variables in both dimensions are not normally distributed (students specializing in informatics have general preferences) and form a bipolar system.

Taking all students into consideration - in contrast to the results of the former longitudinal examination [1] - Kolb's learning variables follow a normal distribution, in other words, no speciality or preference generally typical of the group is to be observed. Normality is supported by Skewness, Kurtosis as well as the quotients of their faults together with the Kolmogorov - Szmirnov test.

The situation is, however, different if the various variables are compared in the individual grades. In grade 9 almost all variables follow a changeable normality distribution, while in year 11 almost none of them do. From this the conclusion is to be drawn that with the progress of studies polarization is more significant, that is the distinguished role of particular learning phases increases in number.

H2. In the dimension of preferred information type and information acquisition, perception the learning variables act similarly to attitudes. In this dimension the preferred learning variable is experience acquisition based on concrete experiences.

In the dimension of preferred information type and information acquisition, perception the mean values of the abstract conceptualization (AC) and concrete experience (CE) variables hardly change beside decreasing deviation values between grades 9 and 11, in other words, these two variables are to be regarded attitudinal. It is mainly the change in the mean values of $\mathrm{CE}$ that is minimal. The change through time of the results is greatly similar to that of former research.

However, there is considerable deviation in the $(\mathrm{AC}, \mathrm{CE})$ preference of these two variables. In this dimension students who participated in the earlier examination had a preference for experience acquisition, while those in the 
present research preferred conceptualization and thought. If in both cases focus falls only on students of informatics, deviation will be similar. To explore the causes of this phenomenon it may be useful to have the same students fill in both questionnaires and then, following the evaluation of the results, the accuracy of either questionnaire is to be checked, too.

Concrete Experience

\begin{tabular}{|c|c|c|}
\hline Accommodator & Northerner & Diverger \\
\hline $11.69 \%$ & $14.29 \%$ & $11.69 \%$ \\
\hline$(3.5 \%)$ & $(6.7 \%)$ & $(6.6 \%)$ \\
\hline [13.8\%] & {$[17.2 \%]$} & [11.1\%] \\
\hline Westerner & Balanced & Easterner \\
\hline $10.39 \%$ & $6.49 \%$ & $9.09 \%$ \\
\hline$(7.6 \%)$ & $(14.2 \%)$ & $(11.5 \%)$ \\
\hline$[8.8 \%]$ & {$[12.5 \%]$} & {$[13.0 \%]$} \\
\hline Converger & Southerner & Assimilator \\
\hline $12.99 \%$ & $6.49 \%$ & $16.88 \%$ \\
\hline$(12.2 \%)$ & $(19.4 \%)$ & $(17.4 \%)$ \\
\hline$[3.7 \%]$ & {$[8.8 \%]$} & [11.1\%] \\
\hline
\end{tabular}

Abstract Conceptualization

Note: Kolb and Kolb's results appear in brackets. First-grade students' in round brackets and arts students' in square ones. [8]

Figure 7

The comparison of learning styles in the nine-region model

H3. In the dimension of preferred information processing learning variables vary in a different way with a progress in studies. Productive application and experimentation is a preferred learning variable.

In the dimension of information processing the mean values of the reflective observation (RO) and active experimentation (AE) variables beside a slight change in distribution show variations with the progress of studies. RO values decrease, AE values increase, the mean values of the two variables deviate, the two lines produce a gap between them, that is the variables of this dimension do not show attitudinal tendencies.

Productive application and experimentation are increasingly becoming the decisive elements of the learning process with the progress in studies. The 
behaviour of the variables of this dimension correspond to that seen in our former examination.

Q1. How does the ranking of learning style change with the progress in studies? Can any characteristic realignment or move be observed?

With the progress in studies the ratio of converger learning style students significantly increases whereas that of assimilator and diverger learning style students decreases. This is in agreement with Kolb's classification of the informatics profession, since the characteristics of converger students are the most suitable for studying this area.

Therefore the learning style of students moves in the direction most appropriate for subject specialities and requirements. Learning style is an individual characteristic, so it would take a longitudinal test to show how it varies from student to student. If this was reinforced, the stable and attitudinal personality indicator property of learning style could by all means be declared false.

Analyzing classifications in the nine-region model it is to be seen that more than $50 \%$ of students have a two-direction strong preference while almost $40 \%$ has a single-direction and approximately $10 \%$ has no preference at all.

In summary it is to be said that $\mathrm{H} 1$ is not at all, $\mathrm{H} 2$ is partly, while $\mathrm{H} 3$ is completely fulfilled, therefore the following theses are stated.

In the dimension of preferred information acquisition, perception learning variables are attitudinal.

In the dimension of preferred information processing learning variables (productive application, experimentation and reflective observation) vary with the progress in studies. Productive application and experimentation are a preferred learning variable.

\section{References}

[1] Tóth, P.: Learning Strategies and Styles in Vocational Education. Acta Polytechnica Hungarica, Vol. 9, No. 3, 2012, pp. 195-216

[2] Coffield, F. - Moseley, D. - Hall, E. - Ecclestone, K.: Learning Styles and Pedagogy in Post-16 Learning: A Systematic and Critical Review. Cromwell Press, Trowbridge, 2004, p. 165

[3] Kolb, D.A. - Fry, R.: Toward an Applied Theory of Experiential Learning. In: Cooper, C.L. (ed.) Theories of Group Processes. John Wiley, London, 1975 , p. 277

[4] Honey, P. - Mumford, A.: The Learning Styles Helper's Guide. Peter Honey Publications, Maidenhead, 2000, p. 70 
[5] McCarthy, B.: Using the 4MAT System to Bring Learning Styles to Schools. Educational Leadership, Vol. 48, No. 2, 1990, pp. 31-37

[6] Kolb, D. A.: The Process of Experimental Learning. In: Kolb, D. A. (ed.) The Experiential Learning: Experience as the Source of Learning and Development. Prentice-Hall, Englewood Cliffs, 1984, p. 288

[7] Kolb, D. A. - Kolb, A. Y.: The Kolb Learning Style Inventory - Version 3.1. 2005 Technical Specifications, HayGroup, Boston, 2005, p. 72

[8] Kolb, D. A. - Kolb, A. Y.: Learning Styles and Learning Spaces: Enhancing Experiential Learning in Higher Education. Academy of Management Learning and Education, Vol. 4, No. 2, 2005, pp. 193-212

[9] Kolb, D. A.: LSI Learning Style Inventory: Self Scoring Inventory and Interpretation Booklet. McBer and Company, Boston, 1985, p. 13

[10] Ösz, R. - Róbert, K.: The Use of Animations in Teaching Technical Drawing. In: Szakál, A. (Ed.): Proceedings of the $7^{\text {th }}$ IEEE International Symposium on Applied Computational Intelligence and Informatics, Timisoara, 2012, pp. 311-314 